\title{
IMPROVEMENTS IN THE PREPARATION OF ALDONIC ACIDS
}

\author{
By C. S. Hudson and H. S. Isbell
}

ABSTRACT

Nearly quantitative yields of aldonic acids are obtained by the use of a buffering salt of an organic acid, such as barium benzoate, during the oxidation of aldoses by bromine water. The buffer greatly increases the speed of the reaction by maintaining a relatively low hydrogen-ion concentration and permits the oxidation of disaccharides or other compound reducing aldoses without complications from hydrolysis. As examples, the preparation of calcium gluconate, the cadmium xylonate-cadmium bromide double salt, and calcium lactobionate are given.

\section{CONTENTS}

I. Introduction.-. Page

II. Preparation of calcium gluconate. 58

III. Preparation of the cadmium xylonate-cadmium bromide double salt_ $\quad 59$

IV. Preparation of calcium lactobionate..... 59

V. Hydrolysis of lactobionic acid to galactose and gluconic acid _... 60

VI. Summary . .

\section{INTRODUCTION}

It is customary to prepare an aldonic acid by the oxidation of the corresponding aldose with bromine water. The reaction is a slow one because of the retarding influence of the hydrobromic acid that is produced during its course. ${ }^{1}$ If the aldose is not a monosaccharide it may be partly hydrolyzed by the hydrobromic acid, with a resulting poor yield of the desired acid. Thus Fischer and Meyer's ${ }^{2}$ oxidations of lactose and maltose to their respective aldobionic acids by bromine water gave yields of only about 30 per cent, and Kunz and Hudson ${ }^{3}$ obtained similar yields in oxidizing neolactose. In these cases the isolation of the aldobionic acid was rendered difficult by the presence of gluconic and galactonic acids resulting from hydrolysis. Recently Goebel ${ }^{4}$ has used the iodine oxidation in alkaline solution to produce

1 Bunzel and Mathews, J. Am. Chem. Soc., 31, p. 464; 1909. Bunzel, J. Biol. Chem., 7, p. 157; 1910.

I Fischer and Meyer, Ber., 22, pp. 361, 1941; 1889.

3 Kunz and Hudson, J. Am. Chem. Soc., 48, p. 2435; 1926.

- Goebel, J, Biol, Chem., 72, p. 801; 1927, 
aldobionic acids in nearly quantitative yield. The method obviously avoids any hydrolysis by acids and should be very suitable in researches where small quantities of sugars are to be oxidized. In larger scale preparations, ${ }^{5}$ however, the cost of the iodine and barium iodide becomes important, and for this reason we have sought to modify the plan of the bromine oxidation with the aim of making it a nearly quantitative reaction suitable for large-scale preparations. The modification which has brought success is a simple one, namely, the addition of a salt of a weak acid to the sugar solution. This acts as a buffer and keeps the hydrogen-ion concentration at a low acidity because the hydrobromic acid is neutralized by the salt and is replaced by the weak acid. The maintaining of the acidity of the solution at a low value results in the reduction of the acid hydrolysis of compound sugars to a negligible amount and in an important increase in the speed of the oxidation. The choice of a suitable buffering salt was made on the basis that its acid and basic constituents would not interfere with the isolation of the aldonic acid. The benzoates of barium and calcium have met these requirements very well. The details of the recommended procedure will be shown by the following examples of typical preparations.

\section{PREPARATION OF CALCIUM GLUCONATE}

Six milliliters of bromine $(0.12$ mole.) were added to an ice-cold solution of $18 \mathrm{~g}$ ( 0.1 mole.) of anhydrous glucose and $60 \mathrm{~g}$ ( 0.15 mole.) of barium benzoate in $750 \mathrm{ml}$ of water. The bromine rapidly dissolved when the solution was shaken and crystals of benzoic acid soon formed. Although a faint, but definite, Fehling's test for reducing substances was obtained when light was not excluded a Fehling's test of the mixture after it had stood 36 hours at room temperature $\left(20^{\circ}\right.$ to $25^{\circ} \mathrm{C}$.) in darkness was negative, indicating the oxidation of all the sugar. The excess bromine was removed by a stream of air and the barium was precipitated quantitatively with sulphuric acid, about $60 \mathrm{ml}$ of $5 \mathrm{~N} \cdot \mathrm{H}_{2} \mathrm{SO}_{4}$ being required. The barium sulphate was filtered off by suction, after the addition of about $10 \mathrm{~g}$ active carbon. The hydrobromic acid was removed quantitatively by the use of lead carbonate $(27 \mathrm{~g})$ followed by silver benzoate $(5 \mathrm{~g})$. A more rapid removal is obtained if silver carbonate $(28 \mathrm{~g})$ is used in place of lead carbonate. Soluble silver and lead salts were then removed as sulphides and the filtrate was concentrated to $200 \mathrm{ml}$ under reduced pressure. The slight quantity of dissolved benzoic acid was largely removed by several extractions with chloroform. The resulting

s Stoll and Kussmal, U. S. Patcnt 1648368, Nov. 8, 1927, describe a method for the preparation of aldonic acids in good yields from the corresponding sugars by chlorine oxidation in the presence of a bromide or iodide. The method is excellent for the commercial preparation of the acids, but the conditions must be carefully controlled; consequently the method is not particularly desirable for general laboratory preparations. 
aqueous solution of gluconic acid was colorless and did not reduce Fehling's solution. It was neutralized with calcium carbonate and concentrated to about $75 \mathrm{ml}$. The addition of 10 volumes of 95 per cent alcohol precipitated granular calcium gluconate, which weighed $21.5 \mathrm{~g}$ after drying at $80^{\circ} \mathrm{C}$. The crude product was recrystallized by solution in $100 \mathrm{ml}$ boiling water, addition of $2 \mathrm{~g}$ active carbon, filtration, concentration of the filtrate to $50 \mathrm{ml}$, and the addition of a small quantity of alcohol. After standing overnight in an ice box the crystals were separated, washed with 50 per cent alcohol, and dried. Yield, $20.2 \mathrm{~g}$. The mother liquor yielded only $0.25 \mathrm{~g}$. The total yield of the recrystallized product was thus 96 per cent of theory. The specific rotation of the calcium gluconate in about 3 per cent aqueous solution was $[a]_{D}^{20}=+8.5$.

\section{PREPARATION OF THE CADMIUM XYLONATE-CAD- MIUM BROMIDE DOUBLE SALT ${ }^{6}$}

Six milliters of bromine $(0.12$ mole. $)$ were added to an ice-cold solution of $15 \mathrm{~g} d$-xylose $(0.1$ mole. $)$ and $60 \mathrm{~g}$ barium benzoate in $1,500 \mathrm{ml}$ water, and the oxidation conducted in the dark at $20^{\circ}$ to $25^{\circ} \mathrm{C}$. The solution gave a negative Fehling test after 36 hours. The excess bromine and the barium were removed as described for the gluconate preparation, and the dissolved benzoic acid was extracted with chloroform. The solution was then boiled with $28.5 \mathrm{~g}$ cadmium carbonate to neutral reaction, filtered, and concentrated to a thin sirup under reduced pressure. Addition of a little alcohol and crystallization overnight in the ice box yielded $29.1 \mathrm{~g}$ of the double salt after washing with alcohol and drying at $80^{\circ}$. The mother liquor yielded $3.2 \mathrm{~g}$ of crystals and the total yield was 90 per cent of theory. The specific rotation of the double salt in 1.5 per cent aqueous solution was $[a]_{D}^{20}=+8.8$. The only previous record seems to be that by C. A. Browne, ${ }^{7}$ who found +7.4 .

\section{PREPARATION OF CALCIUM LACTOBIONATE}

Six milliliters of bromine $(0.12$ mole. $)$ were added to an ice-cold solution of $36 \mathrm{~g}$ a-lactose monohydrate $(0.1$ mole.) and $60 \mathrm{~g}$ barium benzoate $(0.15$ mole. $)$ in $1,500 \mathrm{ml}$ water and the oxidation conducted in the dark at $20^{\circ}$ to $25^{\circ} \mathrm{C}$. The solution gave a negative Fehling test in from 36 to 48 hours. Free bromine and barium were removed as described for the gluconate preparation and the hydrobromic acid was removed by stirring the solution with lead carbonate $(27 \mathrm{~g})$, filtering off the lead bromide and removing the last traces of dissolved bromide

6 Bertrand, Buil. Soc. Chim., 5, p. 554; 1891.

7 C. A. Browne, Inaugural Dissertation, Gottingen, p. 21; 1901. 
with silver benzoate $(5 \mathrm{~g}) .^{8}$ The filtrate then showed no reaction with silver nitrate. Lead and silver were then removed as sulphides and benzoic acid was largely removed by several extractions with chloroform, finally blowing out the dissolved chloroform with air. The resulting solution contains no sugar by Fehling test, is colorless, and represents a nearly pure solution of lactobionic acid.

The substance may be ifurther purified through its basic calcium salt. The addition of $37 \mathrm{~g}$ calcium hydroxide to the hot solution of lactobionic acid results in the slow formation of a fine white precipitate. After 18 hours standing at room temperature the precipitate was filtered off and washed three times with cold water saturated with calcium hydroxide. This precipitate was then suspended in $100 \mathrm{ml}$ water, neutralized with carbon dioxide, and the bicarbonate decomposed by passing air through the warmed solution. The filtrate was concentrated to $50 \mathrm{ml}$ on the water bath by a current of air transferred to a mortar and rubbed with $250 \mathrm{ml}$ of 95 per cent alcohol. The precipitated gummy mass of neutral calcium lactobionate soon became granular on further rubbing. It was triturated successively with $50 \mathrm{ml}$ portions of 80 per cent, 95 per cent, and absolute alcohol, collected on a filter and dried at $80^{\circ} \mathrm{C}$. Yield, $34.5 \mathrm{~g}$. The precipitation of lactobionic acid as its basic calcium salt by calcium hydroxide is not quite quantitative, and it was possible by concentrating the mother liquor and adding alcohol to obtain about $3 \mathrm{~g}$ more of an impure salt which reduced Fehling's solution slightly. Redissolving this in a little water and reprecipitating with alcohol purifies it. Three such purifications yielded $2.1 \mathrm{~g}$ which contained no sugars. The total yield of neutral calcium lactobionate was thus $36.6 \mathrm{~g}$, or 95.7 per cent of theory. The result shows that the procedure of bromine oxidation can be applied to compound reducing aldoses in a way that avoids hydrolysis and gives nearly a quantitative yield of the corresponding compound aldonic acid or its salts.

\section{HYDROLYSIS OF LACTOBIONIC ACID TO GALACTOSE AND GLUCONIC ACID}

It will be recalled that Fischer and Meyer ${ }^{9}$ first carried out this hydrolysis and by it proved that lactose is a galactosido-glucose rather than a glucoside-galactose. So far as we are aware, the preparation has never been repeated, though the beautiful reasoning from which the conclusion is deduced should appeal so strongly to students that the preparation might well be included in laboratory instruction. Doubtless the difficulties which Fischer records in preparing pure

\footnotetext{
8 The hydrobromic acid may be more rapidly removed by using litharge in place of lead carbonate or by omitting lead entircly and using 28 g silver earbonate.

Seo footnote 2. p 57.
} 
lactobionic acid have deterred others from repeating the work. It is believed that the directions which are now supplied improve the method to such an extent that it may be used generally by students.

A solution of $9 \mathrm{~g}$ calcium lactobionate in $100 \mathrm{ml}$ of 7.5 per cent sulphuric acid was heated three hours on the steam bath and then neutralized with calcium carbonate $(8 \mathrm{~g})$. The yellow solution was decolorized with carbon, filtered, and concentrated under reduced pressure to $30 \mathrm{ml}$. The gradual addition of $70 \mathrm{ml}$ hot methyl alcohol precipitated most of the calcium gluconate as a heavy sirup, the galactose remaining in solution. The liquid was decanted and the sirup was extracted thrice with $50 \mathrm{ml}$ hot methyl alcohol. The alcoholic solutions were combined, purified with $1 \mathrm{~g}$ of active carbon, filtered and evaporated to a sirup on a hot plate by a current of air. Galactose crystallized from this sirup on standing overnight. It may be preferable to start crystallization by nucleation. The crystals were washed with 50 per cent cold alcohol and dried at $65^{\circ} \mathrm{C}$. Yield, $2.5 \mathrm{~g}$. The mother liquor was concentrated to a sirup which was dissolved in $50 \mathrm{ml}$ hot methyl alcohol. A small quantity of insoluble material was filtered off and added to the calcium gluconate fraction. The alcoholic solution was concentrated as before and from it was obtained, after nucleation, $0.95 \mathrm{~g}$ crystalline galactose. The total yicld of galactose was $3.45 \mathrm{~g}$, or 80 per cent of theory. After one recrystallization from $10 \mathrm{ml}$ of hot water the sugar showed m. p. $165^{\circ}$ and $[a]_{D}^{20}=79.7$ in aqueous solution.

The amorphous calcium gluconate was dissolved in $15 \mathrm{ml}$ hot water and crystallized from the cooled solution by the addition of alcohol just short of cloudiness (about $5 \mathrm{ml}$ ) and scratching the container. After standing overnight in an ice box the crystals were filtered off, washed with a little cold water, and dried at $65^{\circ}$. Yield, $4.8 \mathrm{~g}$. The mother liquor yielded only $0.1 \mathrm{~g}$ crystals. Total yield, about 95 per cent of theory. After one recrystallization and drying at $65^{\circ}$ the salt showed $[\alpha]_{D}^{20}=+8.2$ in aqueous solution.

\section{SUMMARY}

It is found that the use of a buffering salt of an organic acid, such as barium or calcium benzoate, during the oxidation of aldoses by bromine water greatly increases the speed of the reaction, due to the maintaining of a relatively low hydrogen-ion concentration, and permits the oxidation of compound reducing aldoses, such as lactose, without complications from hydrolysis. The reaction mixture should be kept in the dark for best results. The yields of aldonic acid are nearly quantitative. In the case of lactose it is possible to oxidize it to nearly pure lactobionic acid which can then be hydrolyzed to galactose and gluconic acid, both of which can be obtained in high 
yield. It is believed that the new directions make the method of bromine oxidation of aldoses much more precise and suitable for a wide range of preparations. Examples of the oxidation of glucose, xylose, and lactose are given. It is suggested that the improved directions may be found suitable for laboratory instruction in sugar chemistry as well as for research.

Washington, March 5, 1929. 